\title{
Erratum to: A New Spatio-Temporal Saliency-Based Video Object Segmentation
}

\author{
Zhengzheng $\mathrm{Tu}^{1} \cdot$ Andrew Abel $^{2} \cdot{\text { Lei } \mathrm{Zhang}^{1}}^{1}$ Bin Luo ${ }^{1} \cdot$ Amir Hussain $^{1,2}$
}

Published online: 11 May 2016

(C) Springer Science+Business Media New York 2016

\section{Erratum to: Cogn Comput \\ DOI 10.1007/s12559-016-9387-7}

The authors apologize for having inadvertently forgotten to correctly acknowledge Fig. 3d.

Correct acknowledgement should read:
Figure 3d is reprinted from Torabi, A., Massé, G., Bilodeau, G.-A, An iterative integrated framework for thermal-visible image registration, sensor fusion, and people tracking for video surveillance applications, Computer Vision and Image Understanding, Vol. 116, Issue 2, 2012, pp. 210-221 with permission from Elsevier.

The online version of the original article can be found under doi:10.1007/s12559-016-9387-7.

Bin Luo

luobinahu@163.com; luobin@ahu.edu.cn

Zhengzheng Tu

zhengzhengahu@163.com

Andrew Abel

aka@cs.stir.ac.uk

Lei Zhang

lzhang15@foxmail.com

Amir Hussain

ahu@cs.stir.ac.uk

1 School of Computer Science and Technology, Anhui University, Hefei 230601, China

2 Computing Science and Mathematics, University of Stirling, Stirling FK9 4LA, Scotland, UK 